\title{
The Reactivity of Colloidal Inorganic Nanoparticles
}

\author{
Neus G. Bastús ${ }^{1}$, Eudald Casals ${ }^{1}$, Isaac Ojea ${ }^{1}$, \\ Miriam Varon ${ }^{1}$ and Victor Puntes ${ }^{1,2}$ \\ ${ }^{1}$ Institut Català de Nanotecnologia, Barcelona, \\ 2Institut Català de Recerca i Estudis Avançats (ICREA) Barcelona, \\ Spain
}

\section{Introduction}

The development of functional colloidal inorganic nanoparticles (INPs) has increased exponentially over the past decades offering a "toolbox" ready to be used in a wide range of applications such as materials science, catalysis, biology and medicine (Freitas, 1999; Alivisatos, 2001). This applicability relies on their unique size, morphology and structure, which determines not only their properties but also its reactivity. At the nanometer scale, the confinement of electrons, phonons and photons leads to a new generation of materials which have improved or new physico-chemical properties in comparison with bulk materials. Well-known examples are the size and shape dependence absorption and scattering in noble metal INPs (e.g. Au or Ag), the enhanced fluorescence in semiconductor quantum dots (QDs) (e.g. CdSe or PbS ) and the superparamagnetic moment in magnetic NPs (e.g. iron oxide or cobalt) (Burda et al., 2005). Additionally, as the size of the material is reduced and percentage of atoms at the surface becomes significant, the entire particles become more reactive (Bastús et al., 2008). Thus, in very small crystals, both the thermodynamics and kinetics of reactions can change with size. For instance, a large surface-to-volume ratio can be accompanied by a lowering of phase transition temperatures (Goldstein et al., 1992). Additionally, this high fraction of unsaturated atoms at INP's surface may lead to some instabilities which can further lead to degradation and corrosion processes. Although this secondary processes are often uncontrollable, the feature is extremely useful for catalysis applications (e.g. Pt NPs) allowing reactions at the active sites of their surfaces (Li \& Somorjai, 2010).

All in all, the reactivity of an INP is not only determined by the size, composition and structure of its core. In fact, an INP is the combination of an inorganic core, which determines its physico-chemical properties, and an organic/inorganic shell, which dictates the interfacial interactions by the chemical nature of the organic layer. Therefore, the surface coating play a dominant role when controlling and tuning the reactivity of the particle, determining its solubility and selectivity against a desired target.

In this context, we identify some critical factors that one should take into account when studying the reactivity of INPs (Figure 1). Thus, by reducing the size (or tuning the shape) 
of a nanostructured material, the atomic surface-to-volume ratio increases. In this process, most of the atoms are preferentially located at the edges and kinks of the particle, which dramatically increases its reactivity. Another consequence of the high surface-to-volume ratio of INPs is their high ability to suffer chemical transformations, degradation and corrosion, either caused by the removal of ions which they are in equilibrium with, or by the addition of other ions, leading to its growth. In all cases, these chemical reactions lead to accidental or intended morphological transformations of INPs. Independent of the particular reactivity of the inorganic core, INP's surface coating, its substitution and degradation drastically determine the final interaction between the particle and the surrounding medium. Thus, same core material can interact distinctly depending on the surface nature of the coating layer or its time-dependent evolution. Finally, it is important to consider the interactions between INPs in a colloidal solution. INPs are not isolated entities. On the contrary, they are in a constant Brownian movement which forces their collisions towards an aggregated state. Although this reactivity is often undesirable (physico-chemical properties of INPs are restricted to individual particles in non-physical contact) it can be used as driving force for the formation of more complex structures either by an oriented attached mechanism or by their use as catalysts.

An important prerequisite for boosting the applicability of INPs is developing an in-depth study of INP's reactivity. This condition is especially important in biological and medical systems where the interactions and interferences of INPs with cells and tissues determine not only the potential toxicity of engineered materials but also its biodistribution, degradation and biocompatibility (Casals et al., 2008). The response of nanostructured materials in biological fluids is extremely complex and diverse and depends on a variety of

\title{
Reactivity of Colloidal Inorganic Nanoparticles
}

\author{
(1) Reactivity and Size/Shape of the Inorganic Core \\ (2) Surface Chemistry and Ligand Exchage Reactions \\ 3 Reactivity and (Intended or Accidental) Functionalization: From Targeting to Protein Corona \\ 4) Interactions with Ions: Chemical Transformation, Degradation and Corrosion \\ 5 Cooperative Effects with other Particles in Solution: From Shape Control to Aggregation
}
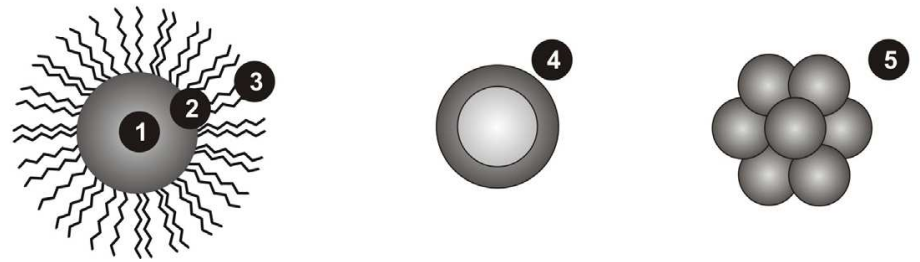

Fig. 1. Reactivity of Colloidal Inorganic Nanoparticles. The critical factors to consider on the study of INP's reactivity are i) Effects of inorganic core's size and shape, ii) the surface molecule substitution and ligand exchange, iii) the particular reactivity of the coating molecule, iv) the interactions with ions present in the colloidal solution and v) cooperative effects with other NPs present in solution. 
involved parameters. INPs can aggregate into microscopic structures or may be encapsulated into surrounding material. NP's surface, which determine its final activity, may experience constant modifications such as corrosion or degradation.

In this context, this chapter explores the reactivity of colloidal INPs. It focuses on the particular physical-chemical properties of INPs and in the understanding of the factors that determine its chemical reactivity and therefore its applicability, in nanobiomedicine and catalysis among others. We summarize the potential reactivity of INPs attributed either to their size, shape, chemical composition and structure, focussing of the special features that make them unique and potentially more toxic and risky. Thus, interactions of INPs with surrounding environments will determine their stability while (intended or accidental) surface coating defines much of their bioactivity. Consequences of this are the different final bioactivity of the same element depending on their surface charge (INPs positively charged predominantly attach negative biological surfaces as cell membranes, leading to cell death) and the nature of the non-specific coating that evolves as time progresses leading to different responses at different exposure times. Additionally, toxicological aspects associated to the reactivity of INPs (size, shape, chemical composition and structure) will be widely discussed. The aim of this chapter is not to provide in-depth insights into INP's features, but to tackle the study from a holistic perspective, in the framework of INP's full life cycle.

\section{Reactivity and morphology}

\subsection{Reactivity and size}

The size of nanostructured materials determines, among others, its reactivity. The reasons are clear and easily defined. Whereas in a bulk material, surface atoms contribute only a relatively small fraction (only a few per cent) of the total number of atoms, in INPs the curvature radii is so high that all the atoms of the particle lay close or at the surface of the kinks, steps and edges. Therefore, this small particles contain all (or almost all) surface atoms, and those atoms have lower coordination numbers than in the bulk material. Since the reactivity of a single atom tend to increase as its coordination decreases, it follows that the reactivity of nanostructured materials increases as particle size decreases. Thus, in the case of a nanocrystal (NC) with a face-centered cubic (f.c.c.) structure, when the size of the crystal is small enough $(1 \mathrm{~nm})$ all the atoms of the particle are located at the surface (and edges) while it decreases to $50 \%$ when the size is $2 \mathrm{~nm}$. For larger diameters, the number of surface atoms is extremely low $(<5 \%$ for $20 \mathrm{~nm})$ and the reactivity of the crystal is determined by the quality of the surface, i.e., the number steps, kinks and terraces of its surface (Figure 2-A). Thus, there is a combined effect in INPs. First, greater accessibility to all constituent (surface) atoms and secondly, enhanced reactivity because of the low coordination number they exhibit.

Among other features, the size of INPs has been extensively investigated for their implications in catalysis applications since it deeply impacts on both surface structure and electronic properties. Rather than by the exact number of atoms in a cluster (particle size and size distribution), the catalytic reactivity is determined by the arrangement of the surface atoms (number of edges and corners) and the exposure of certain crystallographic planes. Especially interesting is the case of Au NPs which, although considered chemically 
inert, has been found to be a very effective catalyst for sizes below $5 \mathrm{~nm}$ (Hvolbaek et al., 2007). Catalysts based on Au NPs allow significant lower reaction temperatures than used in existing cases which is promising for the development of energy efficient processes. Thus, $\mathrm{Xu}$ et al. (Xu et al., 2006) showed that unsupported nanoporous $\mathrm{Au}$, with pores sizes less than $6 \mathrm{~nm}$, made by selective dissolution (de-alloying) of $\mathrm{Ag}$ from $\mathrm{Ag} / \mathrm{Au}$ alloy, are active catalysts for $\mathrm{CO}$ oxidation. Further evidences for the scaling of the catalytic activity with the number of corner atoms were provided by Overbury et al. (Overbury et al., 2006) by correlating the $\mathrm{CO}$ oxidation activity of a $\mathrm{Au} / \mathrm{TiO}_{2}$ catalyst with $\mathrm{Au}$ particle size.
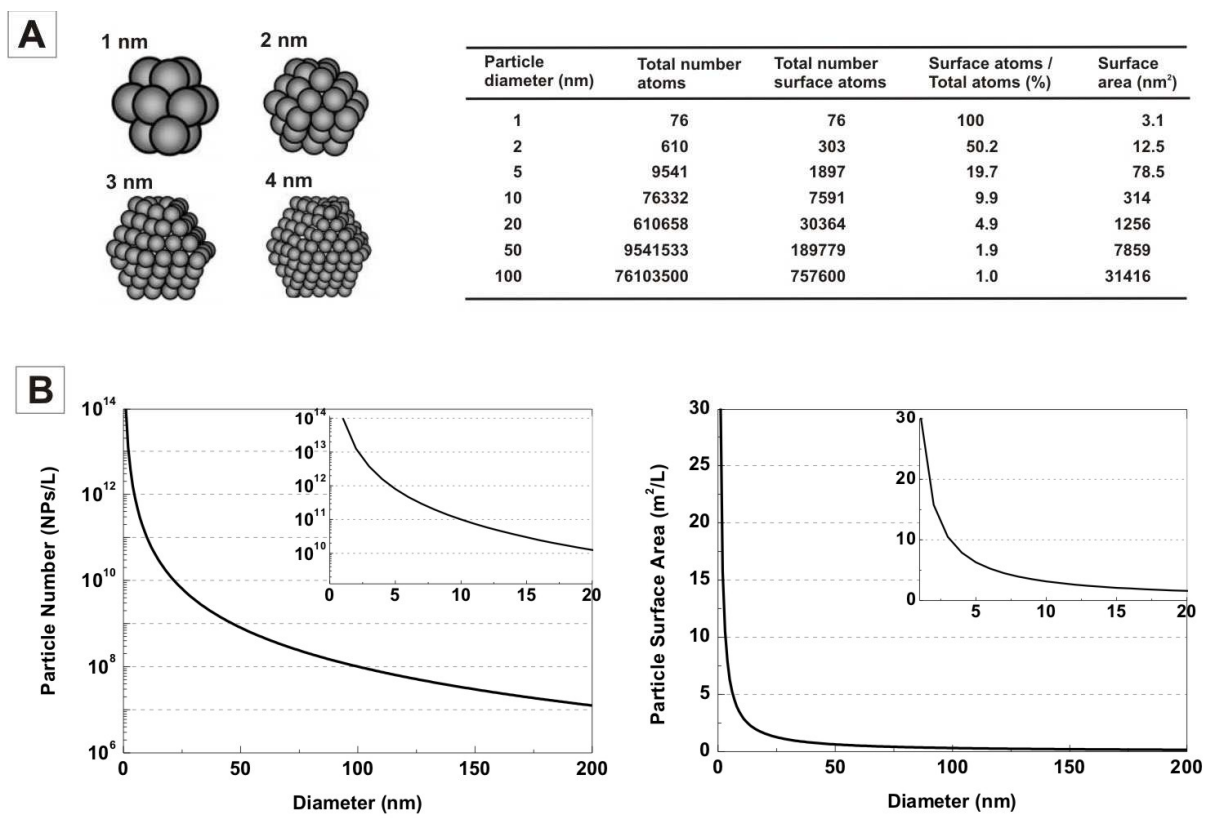

Fig. 2. Core,surface and edge distribution of atoms in inorganic nanoparticles. (A) Atomic distribution in icosahedral nanoparticles from 1 to $4 \mathrm{~nm}$ in diameter (left) and total number of atoms, surface atoms, surface-to-volume ratio and total surface area for Au nanoparticles of different sizes. (B) Particle number (left) and total particle surface area (right) for a colloidal solution which contains $1 \mathrm{~g} / 1 \mathrm{~L}$ of Au atoms.

Another effect of reducing the size of the nanocrystal is the increase of the particle number for a given mass. Thus, considering a colloidal solution of Au NPs with a fixed mass $(1 \mathrm{~g} / 1$ L) and density $\left(19 \mathrm{~g} / \mathrm{cm}^{3}\right)$, as the particle size decreases 10 times, the concentration increases by a factor 1000 (Figure 2-B). This phenomenon has been a source of controversy when studying the toxicity of INPs as a function of their size, being often shown that smaller particles exhibit more acute toxicity and had higher inflammatory effects that small ones. Toxicity and INP's dose are directly interrelated. Almost any type of nanomaterial has been found to be toxic at high concentrations, and vice versa, nothing is toxic at enough small doses. It is often observed that doses used in in vitro studies are very high while there is little consideration or discussion about the realistic in vivo exposures (Oberdorster et al., 2005). For instance, $100 \mu \mathrm{g}$ of INPs/ml in cell culture media, labelled as a low dose, is high and 
unlikely to be encountered in vivo. Considering the concentration of as-synthesized engineered INPs, where colloidal synthesis represents the major technique to get individual size and shape controlled NPs, the standard concentrations are ranging from $10^{12}$ to $10^{16}$ INPs $/ \mathrm{ml}$, depending on the material, that corresponds to an upper limit for very dense materials of few $\mathrm{mg} / \mathrm{ml}$. Alternatively, total surface area has been found to be a better doseparameter than particle mass or particle number in toxicity studies (Oberdörster, 2000; Oberdörster et al., 2000), especially when comparing particles of different sizes. Furthermore, it has been hypothesized that phenomena that operate at low realistic doses are likely to be different from those operating at very high doses when organism or cell defences are overwhelmed (Oberdorster et al., 2005). In addition to that, it is important pointing out that INP's concentration may change in different parts of the body, either by aggregation or accumulation (trapping) in special organs as the liver or kidneys (Bastús et al., 2008; Casals et al., 2008).

The increase of INP's concentration as decreasing INP's size withstands with an increase of the total surface area, and hence the reactivity of the system. This enhancement on reactivity could be either beneficial (antioxidant, carrier capacity for drugs, increase uptake and interaction with biological tissues) or disadvantageous (toxicity, instability, induction of oxidative stress) depending on the intended use and the material used (Bastús et al., 2008). For instance, small $\mathrm{CeO}_{2}$ INPs are known to exhibit superior antioxidant properties due to the presence of oxygen vacancies on its surface and a cycle of dual oxidation states $\left(\mathrm{Ce}^{3+}\right.$ and $\mathrm{Ce}^{4+}$ ), which makes them extremely useful as a quenchers of Reactive Oxygen Species (ROS) in biological systems (Karakoti et al., 2008; Garcia et al., 2010). On the other hand, INP's degradation increases as INP's size decreases.

\subsection{Reactivity and shape}

Similarly, the reactivity of a particle also depends on its shape. As explained above, INP's reactivity is directly associated to surface atoms, whose number is determined not only by particle's size but also by the distribution of atoms within the particle. Therefore, particle's shape is as important as size when studying INP's reactivity. This dependence can be easily evaluated by calculating the number of surface atoms for different particle's geometry while

keeping constant the total number of atoms in the particle (Figure 3). Thus, in the case of 10 nm spherical Au NPs, only $\sim 10 \%$ of atoms are located at the surface of the particle while this number increases up to $\sim 29 \%$ when same number of atoms are distributed forming a disk. Although obtaining much more smaller values, same tendency was observed in larger particles. Thus, $\sim 0.47 \%$ are surface atoms in a $200 \mathrm{~nm}$ spherical Au NP whereas this value increases up to $\sim 0.53 \%$ or to $\sim 1.46 \%$ when moving to anisotropic shapes such as cubes and disks. Beyond the number of surface atoms, INP's reactivity is also directly determined by the quality of the surface. Therefore, atoms in flat surfaces, which have a higher degree of coordination than spheres, have a lower reactivity compared to the atoms on vertices and edges present in the anisotropic shapes. This allows a greater portion of atoms or molecules to be oriented on the surface rather than within the interior of the material, hence allowing adjacent atoms and molecules to interact more readily. As further discussed, this fact has important consequences on the functionalization of INPs, in particular when studying how its surface curvature affects the organization of molecules (as alkanethiols) attached at their surfaces. Thus, the degree of packaging of molecules attached to relatively small Au NPs 
(less than $20 \mathrm{~nm}$ ) is significantly lower than their large particle counterparts, allowing for less density of molecules to be attached to the highly curved surfaces than to the larger flatter surfaces, when equal areas are compared.

Moreover, anisotropic shapes expose different crystal faces. In fact, shape control is usually achieved by the selective interaction of surfactant molecules with a particular crystallographic facet, which leads to a preferential growth along a certain direction. Well known examples are the synthesis of anisotropic semiconductor NCs (Kumar \& Nann, 2006). For semiconductor systems, where different crystal planes are chemically distinct, this has been demonstrated by using mixtures of surfactants. Thus, Alivisatos' group induced anisotropy in CdSe spherical NCs by using a tri-n-octylphosphine oxide (TOPO) and phosphonic acids, instead of TOPO alone (Peng et al., 2000). Resultant CdSe nanorods displayed many important property modifications compared to spherical NCs, such as polarized light emission (Hu et al., 2001). In continuation of this success, other complex morphologies such as arrows and tetrapods, were successfully synthesized (Manna et al., 2000), all of them explained on the basis of the selective adsorption of surfactants on different crystallographic faces. For the fcc noble metals, the low-energy $\{111\}$ and $\{100\}$ facets possess similar surface energies and, therefore, chemical reactivities, which limit the number of candidate molecules for directing shape control by selective binding preference for different crystal planes. Specially interesting is the case of the polymer poly(vinyl pyrrolidone) (PVP) since it has been demonstrated to stabilize the lowest-energy crystal facets of these fcc crystal systems to give colloidal structures bounded by $\{111\},\{100\}$, and $\{110\}$ planes (Tao et al., 2008).

\begin{tabular}{|c|c|c|c|c|c|c|c|c|c|}
\hline \multirow[b]{2}{*}{$\begin{array}{l}\text { Particle } \\
\text { diameter (nm) }\end{array}$} & \multirow[b]{2}{*}{$\begin{array}{l}\text { Total number } \\
\text { atoms }\end{array}$} & \multicolumn{2}{|c|}{ Sphere } & \multicolumn{2}{|c|}{ Cube } & \multicolumn{2}{|c|}{ Rod } & \multicolumn{2}{|l|}{ Disk } \\
\hline & & $\begin{array}{l}\text { Surface atoms } / \\
\text { Total atoms (\%) }\end{array}$ & $\begin{array}{l}\text { Surface } \\
\text { area }\left(\mathrm{nm}^{2}\right)\end{array}$ & $\begin{array}{l}\text { Surface atoms } / \\
\text { Total atoms (\%) }\end{array}$ & $\begin{array}{l}\text { Surface } \\
\text { area }\left(\mathrm{nm}^{2}\right)\end{array}$ & $\begin{array}{l}\text { Surface atoms I } \\
\text { Total atoms (\%) }\end{array}$ & $\begin{array}{l}\text { Surface } \\
\text { area }\left(\mathrm{nm}^{2}\right)\end{array}$ & $\begin{array}{l}\text { Surface atoms I } \\
\text { Total atoms (\%) }\end{array}$ & $\begin{array}{l}\text { Surface } \\
\text { area }\left(\mathrm{nm}^{2}\right)\end{array}$ \\
\hline 10 & 76080 & 9.4 & 314 & 10.6 & 354 & 13.5 & 451 & 29.2 & 971 \\
\hline 20 & 608642 & 4.7 & 1256 & 5.3 & 1416 & 6.8 & 1804 & 14.5 & 3886 \\
\hline 30 & 2054169 & 3.1 & 2826 & 3.5 & 3187 & 4.5 & 4059 & 9.7 & 8743 \\
\hline 50 & 9512937 & 1.9 & 7850 & 2.1 & 8854 & 2.7 & 11274 & 5.8 & 24287 \\
\hline 70 & 26095556 & 1.35 & 15394 & 1.5 & 17364 & 1.9 & 22109 & 4.2 & 47629 \\
\hline 100 & 76080340 & 0.94 & 31400 & 1.06 & 35419 & 1.35 & 45097 & 2.9 & 97151 \\
\hline 200 & 608828006 & 0.47 & 125600 & 0.53 & 141676 & 0.67 & 180386 & 1.46 & 388686 \\
\hline
\end{tabular}

Fig. 3. Shape dependent surface atomic distribution of nanoparticles . Total number of atoms was kept constant (considering Au spheres of different diameters) while the number of surface atoms and the surface area was calculated by different geometries. Rod particles were considered to have a cubic section with a long length 10 times larger than the short length and disk particles have a diameter 10 times larger than their height.

The possibility of controlling the exposition of different crystal faces by tuning NC's morphology has been widely exploited for its applicability in catalysis, where the yield and selectivity of the catalyzed reaction depends on the nature of the catalyst. This dependence has been observed in the Pt-catalyzed hydrogenation of benzene where the $\{100\}$ surface 
yields only cyclohexane while the $\{111\}$ surface gives both cyclohexene and cyclohexane (Bratlie et al., 2007). Similarly, electron-transfer reaction between hexacyannoferrate and thiosulfate has been catalyzed by Pt nanocrystals with different shapes obtaining that tetrahedral NCs, completely bound by $\{111\}$ crystal facets, exhibit the highest catalytic activity whereas cubic nanocrystals exhibit the lowest activity (Tao et al., 2008). Although promising results have been obtained, the largest obstacles facing shape-controlled nanocatalysis are compatible surface chemistry and shape retention. Catalytic studies need naked surfaces, which is never the case of colloidal NCs, protected by a layer of organic material. Although removing these stabilizing agents may be required to create accessible active sites, it is difficult to do it without inducing significant morphological changes via surface reconstruction, particle ripening, melting, or oxidation (Barghorn et al., 2005).

The correlation between reactivity and INP's shape has also relevant consequences on the study of the potential toxicity of nanomaterials. A typical example is the common synthesis of $\mathrm{Au}$ NPs in the presence of hexadecyltrimethylammonium bromide (CTAB). CTAB is a toxic surfactant that strongly binds to the surface of Au NPs confining its growth and conferring stability. Whereas at relative low CTAB concentrations spherical Au NPs are obtained, at high concentrations (beyond the second critical micellar concentration threshold), CTAB forces crystal growth to anisotropic shapes leading to rod-like structures (Nikoobakht \& El-Sayed, 2003). This correlation between CTAB concentration and morphology can be understood by a stronger interaction between the atoms at the surface of the rod particle and $\mathrm{CTAB}$ molecules. In fact, these hypothesis correlates with shapedependent toxicity results. Thus, after observation that CTAB-stabilized Au NPs were toxic (rods and spheres), similar cleaning processes lead to non-toxic spheres but still toxic rods (Connor et al., 2005).

\section{Corrosion and interactions with ionic species}

\subsection{Degradation and corrosion}

Another consequence of the high surface-to-volume ratio and low atomic surface coordination of nanostructured materials is its degradation, much more relevant at the nanoscale than in bulk materials. INPs are constantly exposed to degradation processes, which reduce them to their constituent atoms either by chemical reactions with the surrounding media or easily because the degradated state is thermodynamically more favorable.

All chemical reactions follow the laws of the chemical equilibrium between reactants and products even though this equilibrium may be displaced to one of the components. This simple idea can be applied to an INP's colloidal solution. A colloidal INP's solution is a chemical reaction where the reagent is the precursor compound and the product is the synthesized colloidal solution. In this regard, it has been observed when synthesizing INPs that only a percentage of initial precursor used is finally converted to INPs. There is therefore an equilibrium between INPs and precursor ion (Figure 4). This fact has important implications not only on the final INP's morphology but also when studying its toxicity. First, because it can lead to the morphological evolution of colloidal INPs (such as a broadening of the size distribution), following an Ostwald ripening process. Additionally, it is especially important when calculating INP's concentration from the initial amount of 
precursor weighted. As previously mentioned, toxicity and INP's concentration are directly interrelated and hence concentration value must be always corrected by the precursor to INPs conversion rate. Moreover, this chemical equilibrium is also important when purifying INPs (by means of precipitation or other washing methods) since this process displace the equilibrium towards colloidal species, which leads to the new release of ions at the expense of INPs' dissolution and further modifications on INPs' morphology. This decrease of ion concentration in solution is, in fact, a general phenomenon when studying INP's full life cycle since scavengers (as serum proteins), or the simple sample dilution can deplete ionic concentration, forcing the partial or complete INP's degradation. Although degradation process is difficult to prevent, it is possible to protect INPs by designing engineered coatings. Thus, several studies show how the encapsulation of INPs in micelles or their functionalization with self-assembled monolayers (SAM) of molecules could protect them from corrosion.

\subsection{Toxicity and ion release}

A critical parameter when studying the potential toxicity of INPs is the composition and reactivity of the materials used in their synthesis. Due to the abundance and high reactivity of metals in the presence of oxygen, metal oxide INPs are especially interesting. Metal oxide surfaces are known to be very biocompatible due to their charge organization at the surface (Weissleder et al., 1989). However, not all the oxide INPs display the same toxicity (Gojova et al., 2007). Different stochiometries give different crystal structures with different properties and different surfaces, leading to different potential toxicities. This is the case of magnetic conductors (magnetite), magnetic insulators (maghemite) or non-magnetic insulators (hematite) where the reactivity of conducting and non-conducting materials and the degree of aggregation of magnetic and non-magnetic particles can be significantly different.

A

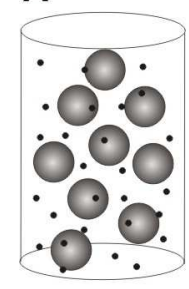

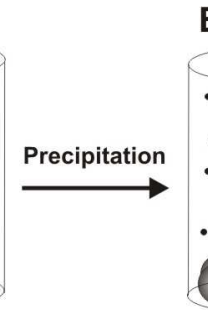

B

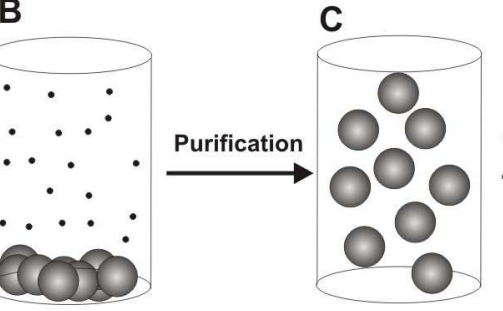

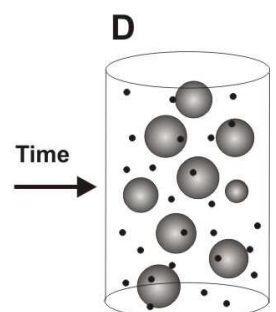

Fig. 4. Degradation of inorganic nanoparticles. As-synthesized INPs in equilibrium with precursor species (A). Purification and washing processes displace the equilibrium towards colloidal species (B, C), which leads to the new release of ions at the expense of NP's dissolution. On this stage, INP's morphology is modified due to an Ostwald ripening process $(\mathrm{D})$.

Toxicity is frequently related to the ability of nanostructured materials to release ions. In nanostructured metallic implants, were wear-corrosion greatly contributes to ion release processes, it often correlated with health problems (Ito et al., 2001). Even fairly stable oxides, as in the case of magnetite $\left(\mathrm{Fe}_{3} \mathrm{O}_{4}\right)$, may continue oxidizing when exposed to biological environments (Lazaro et al., 2005). In these cases, released ions may undergo chemical 
transformations which may lead to different chemical species, with altered isotopic composition, electronic or oxidation state and molecular structure (Auffan et al., 2009), which may modify its biological impact (Gupta \& Gupta, 2005). In other cases, the corrosion process can be toxic by itself, modifying the redox biochemistry activity of the surrounding biological media and leading to an oxidative stress both in vivo and in vitro (Oberdorster et al., 2005). For example, Derfus et al. (Derfus et al., 2004) reported the intracellular oxidation and toxicity of CdSe QDs associated to the release of $\mathrm{Cd}^{2+}$ cations $\left(\mathrm{Cd}^{2+}\right.$ binds to mitochondria proteins leading to hepatic injuries) while Franklin et al. (Franklin et al., 2007) revealed comparable toxicity of $\mathrm{ZnO}$ INPs $(30 \mathrm{~nm})$ and $\mathrm{ZnCl}_{2}$ salts, therefore presuming that effects may be attributed to $\mathrm{Zn}$ ions released from ZnO INPs. All in all, the environmental and health effects of INPs have contributed to study corrosion processes on nanomaterials.

\subsection{Reactivity and ionic/cationic Interactions}

Relevant consequences of INP's reactivity are their chemical transformations via insertion or exchange of atoms. In extended solids, reactions involving chemical transformations are in general very slow because of high activation energies for the diffusion of atoms and ions in the solid. However, it has been proved that cation exchange reaction can occur completely and reversibly in ionic NCs at room temperature with unusually fast reactions rates. A clear example is the interaction of semiconductor nanocrystals with metal cations, CdSe reacts with $\mathrm{Ag}^{+}$ions to yield $\mathrm{Ag}_{2} \mathrm{Se} \mathrm{NCs}$ by the forward cation exchange reaction, and vice versa, $\mathrm{Ag}_{2} \mathrm{Se}$ reacts with $\mathrm{Cd}^{2+}$ ions to yield CdSe, for the reverse cation exchange reaction (Figure 5-A) (Son et al., 2004). While this reaction is extremely fast $(<1 \mathrm{~s})$ for NCs, similar experiments carried out with micrometer-sized powders of CdSe found the cation exchange to be virtually prohibited. The speed of the reaction can be explained on the basis of simple scaling of the size in diffusion-controlled reaction schemes, when the reaction time is roughly proportional to the square of the size. This cation exchange reaction, initially investigated with $\mathrm{Ag}^{+}$ions, was easily extended not only to other cations but also to the formation of complex hybrid structures with precise structural and compositional tailoring (Zhang et al., 2010). Thus, CdSe NCs can be transformed into CuSe and PbSe though the cations exchange reaction with $\mathrm{Cu}^{2+}$ and $\mathrm{Pb}^{2+}$ ions while $\mathrm{Au}-\mathrm{CdS}-\mathrm{CdSe}$ core-shell-shell hybrid structures can be obtained from Au-Ag core-shell INPs.

Another chemical transformation extremely interesting is the galvanic corrosion between two different metals and/or alloys having electrical contact with each other. This effect is a coupled reaction where the more active metal corrodes at an accelerated rate and the more noble metal corrodes at a retarded rate. Galvanic replacement has been widely exploited for the obtention of hollow nanostructures of metals by reacting metals solutions ( such as $\mathrm{Au}^{3+}$, $\mathrm{Pt}^{2+}$, and $\mathrm{Pd}^{2+}$ salts) with pre-formed NCs of a more reactive metal (Sun et al., 2002). An example is the synthesis of $\mathrm{Au}$ nanoboxes from Ag nanocubes (Figure 5-B). Because the standard reduction potential of $\mathrm{AuCl}^{4-} / \mathrm{Au}$ pair is higher than the one of $\mathrm{Ag}^{+} / \mathrm{Ag}$ pair, $\mathrm{Ag}$ nanocubes suspended in solution can be oxidized by $\mathrm{HAuCl}_{4}$. The elemental $\mathrm{Au}$ produced in this reaction is confined to the vicinity of the template surface, nucleating into very small particles and growing, forming a thin shell around the Ag template. This process continues until the Ag template has been completely consumed. At the last stages of the reaction, $\mathrm{Au}$ shells reconstruct their walls into highly crystalline structures via processes such as Ostwald ripening. These Au shells have a morphology similar to that of the Ag templates, with their 
void sizes mainly determined by the dimensions of the templates. These chemically transformed particles exhibit plasmonic properties completely different from those solid (even made of the same metal).

\section{A- Cation Exchange}
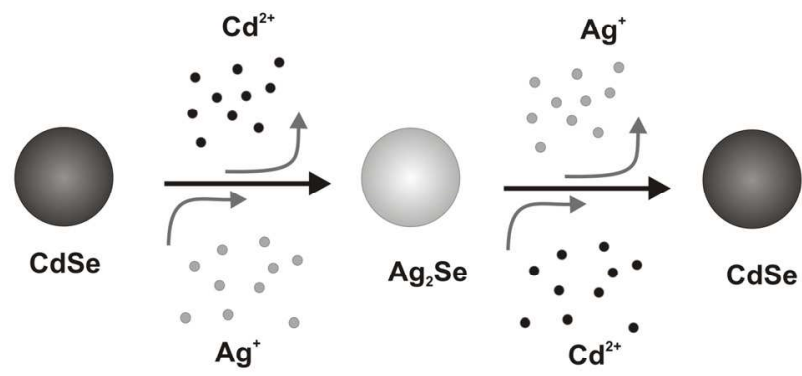

\section{B- Galvanic Replacement}

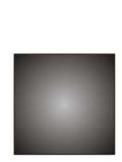

$\mathrm{Ag}$

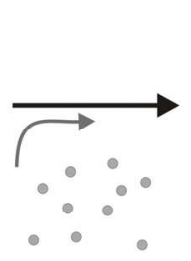

$\mathrm{Au}^{3+}$
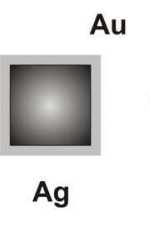

Au

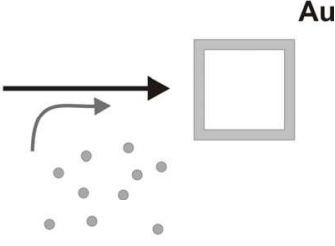

$\mathrm{Au}^{3+}$

\section{C- Kinkerdall Effect}

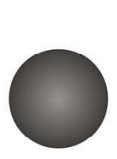

$\mathrm{Fe}$
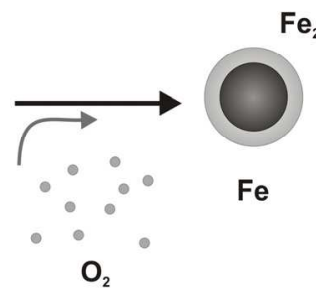

$\mathrm{Fe}_{2} \mathrm{O}_{3}$

$\mathrm{Fe}_{2} \mathrm{O}_{3}$

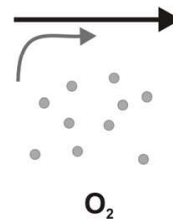

Fig. 5. Chemical transformations of inorganic nanoparticles via insertion or exchange of atoms. (A) Cation exchange reactions in semiconductor nanocrystals. (B) Galvanic replacement in metal nanoparticles, (C) Kinkerdall effect in magnetic nanoparticles.

Solid diffusion processes are also a synthetic strategy rather used to prepare hollow solid materials. This phenomenon, called Kirkendall effect, results from the difference of the solid-state diffusion rates of the reactants in an alloying or oxidation reaction (Figure 5-C). A significant difference in the diffusion coefficients produce an accumulation of vacancies at the interface of the two components that can lead to the formation of cavities. Thus, the atomic diffusion occurs through vacancy exchange and not by interchange of atoms. The first experimental proof of this phenomenon, originally identified in metal alloys, was 
reported by Smigelkas and Kirkendall in 1947 (Smigelskas \& Kirkendall, 1947). Subsequently, this process was extended into other systems such as oxides, sulfides and nitrides, in which the metallic atoms diffuse faster. To mention some examples at the nanoscale, Alivisatos and co-workers described the formation of hollow oxides (CoO) and chalcogenides $\left(\mathrm{Co}_{3} \mathrm{~S}_{4}\right)$ nanostructures through the Kirkendall effect employing Co NCs as starting material and reacting them with oxygen and sulfur, respectively, at $182{ }^{\circ} \mathrm{C}$ (Yin et al., 2004). As well, Cabot et al. studied the vacancy coalescence during the oxidation process of iron INPs in solution with a controlled oxygen flow and temperature, which leads to the formation of hollow iron oxide INPs. (Cabot et al., 2007). Also has to be considered that the properties of the INPs exposed to transformation processes can be affected. Thus, INPs can lose the applicability in where they are interesting for. Worthy to mention is the work reported by Cabot et al. who studied the magnetic properties and surface effects in hollow maghemite INPs where the single dipole cannot stay at the core of the INPs (Cabot et al., 2009).

\subsection{Morphology control and seeded growth methods}

The reactivity of colloidal INPs against ionic precursor molecules can be used to precisely control INP's morphology following seeded-growth methods in which pre-synthesized INP's are used as catalysts for the growth of larger particles. The catalyst is usually a colloidal INP that is either injected into a solution together with the precursor molecules needed to growth the desired crystal, or is nucleated in situ. Well known examples are the synthesis of nanowires of CdSe, InP, Si and Ge (Trentler et al., 1995; Ahrenkiel et al., 2003; Grebinski et al., 2004) from semiconductor seeds and the size and shape control of Au NPs (Bastús et al.; Pérez-Juste et al., 2005). In the later case, the reduction of the metal salt, such as $\mathrm{HAuCl}_{4}$, was typically carried out in an aqueous system in the presence of ligands such as cetyltrimethylammonium bromide $(\mathrm{CTAB})$ or sodium citrate. (Figure 6). Even more complex structures can be synthesized by taking advantage of NP's reactivity. This is the case of hybrid NCs (HNCs), composed by the combination of different materials assembled together in a single nanostructure. A clear example is the combination of fluorescence and magnetism into a single nanostructure which represents the possibility of bio-detect and bio-separate biological entities. Specially interesting are HNCs based on semiconductor materials, mainly for their utility on optoelectronic, photovoltaic and catalysis applications, where the combination of metal and semiconductor domains allows photo-generated charge carriers performing redox reactions with high efficiency (Kamat, 2007). In the case of semiconductor materials with anisotropic shapes (such as rods, tetrapods or even pyramids), the higher reactivity of the polar facets opens up the possibility of nucleating a second material exclusively at these locations. This idea has been clearly demonstrated for the growth of Au domains onto CdSe NCs (Mokari et al., 2004; Meyns et al., 2010).

\subsection{Adsorption, alloying and environmental remediation}

Taking advantage from their reduced size, large surface area and highly reactive surface sites, nanomaterials have become particularly attractive as separation media for environmental remediation (Diallo \& Savage, 2005; Savage \& Diallo, 2005; Karn et al., 2009). For certain reduced diameters, INPs are sustained by Brownian dispersion avoiding sedimentation, which means that they can be maintained exploring the volume without 
additional agitation. This capacity to be dispersed in groundwater allows them to travel farther than larger macro-sized particles, thus achieving a wider distribution and permitting the whole volume to be quickly scanned with a relatively low number of particles. For example, in a rough estimation, a $10 \mathrm{~nm}$ metallic INP in water at room temperature (RT) will experience Brownian relaxation in the order of the nanosecond, and after each Brownian step in solution it will move about 10 to $20 \mathrm{~nm}$. Therefore, a typical INP concentration of few $\mathrm{nM}$ will explore the total volume in the time order of the cent-second (assuming a $10 \%$ efficiency, i.e. the INP would repeat a previous position up to 10 times before visiting a new one).
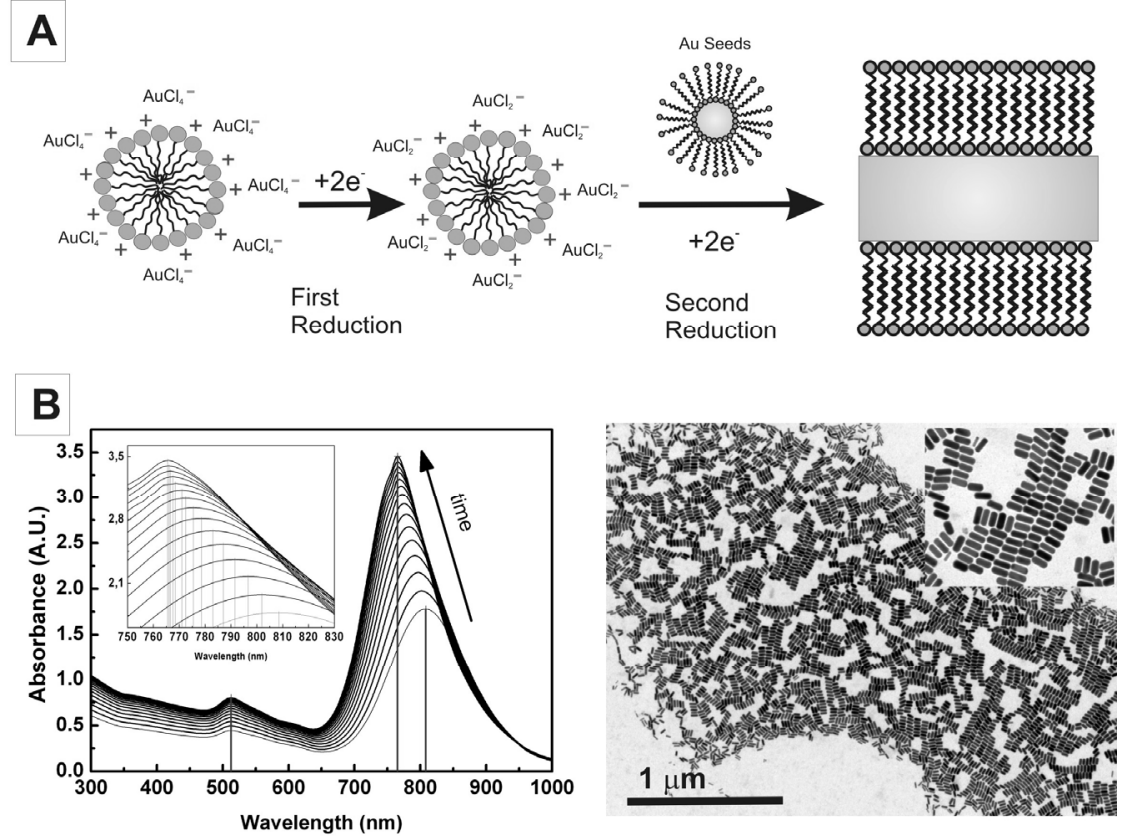

Fig. 6. Reactivity and shape control. Growth of Au nanorods in the presence of a seed NCs used as catalyst. (A) The transport of Au ions bound to the CTAB micelles to the growing seed particles is controlled by the double layer interaction. The first reduction is confined in metallomicelles while the second reduction only begins after the seed solution is added.

(B) Vis-NIR absorption spectra of a representative Au NRs solution growing from Au seeds as a function of time from 20 to $60 \mathrm{~min}$ after the addition of seed to the growth solution and morphological characterization of resultant particles by transmission electron microscopy.

The high adsorption capacity of nanomaterials for certain pollutants has been demonstrated in many cases. For example, heavy metals have been effectively removed from contaminated water, as is the case of $\mathrm{Cr}^{+6}$ and $\mathrm{Cr}^{+3}$ employing maghemite (Hu et al., 2005) and silica NPs (López \& Castaño, 2008) respectively, or $\mathrm{Hg}^{+2}$ with alumina INPs (Pacheco et al., 2006). In addition, the magnetic properties of some nanomaterials have been employed for magnetic separation after the absorption process, which allowed mixtures of differentsized INPs to be separated by the application of different magnetic fields (Yavuz et al., 
2006). With this methodology $\mathrm{As}^{+3}$ and $\mathrm{As}^{+5}$ could be eliminated from drinking water supplies employing iron oxide INPs, which involved the formation of weak arsenic-iron oxide complexes at INP's surface. An overview on the use of nano-size iron particles for environmental remediation has been reported by Zhang et al. (Zhang, 2003) Furthermore, the incorporation of some other metal ions, such as $\mathrm{TiO}_{2}$, into the lattice structure of iron oxide enhances the material properties namely surface adsorption and photo-induced catalysis (Gupta \& Ghosh, 2009). The surface functionalization is also a very important factor in environmental remediation since it can enhance the affinity towards specific target molecules. A well known example is the case of magnetite INPs functionalized with dimercaptosuccinic acid, where the thiolated ligand acts as an effective sorbent for toxic soft metals such as $\mathrm{Hg}, \mathrm{Ag}, \mathrm{Pb}, \mathrm{Cd}$ and $\mathrm{Ti}$ while As binds to the iron oxide lattices (Yantasee et al., 2007). Alternatively, specific functionalization can also be used on organic-inorganic nanocomposite semiconductor systems to trap organic molecules and then promote their complete degradation making use of the photocatalytic properties (Beydoun et al., 1999). A comprehensive overview of the different manufactured nanomaterials along with the pollutants they could potentially remediate has been reviewed elsewhere (Karn et al., 2009).

Apart from the adsorption capacity, the chemistry of metal alloying has also been used for sequestration of mercury. Thus, in the presence of Au (Henglein \& Giersig, 2000; Lisha et al., 2009) or Ag NPs (Katsikas et al., 1996), the $\mathrm{Hg}^{2+}$ atoms present in solution can easily be reduced followed by adsorption on the INP's surface and further amalgam formation. As a consequence of the mercury uptake, remarkable morphological transformations can be observed leading to non-spherical shapes and coalescence of particles to an increasing extent. The optical absorption spectra of the mercury containing Au particles is shifted and damped. Similar chemical and optical transformations of spherical CdTe and CdSe NCs into anisotropic alloyed $\mathrm{CdHgTe}$ and $\mathrm{CdHgSe}$ particles respectively have been observed in the presence of mercury, which have been attributed to the positive redox potential of mercury species (Taniguchi et al., 2011).

\section{Reactivity and surface chemistry}

Independent of particle size and core composition and structure, the surface coating of the nanostructured material play a dominant role when controlling and tuning the reactivity of the particle and defining its bioactivity. Although as-synthesized INPs present excellent physical and chemical properties, they do not always possess suitable surface properties for specific applications. Then, it is necessary to modify their surface for several reasons such as solubility and stabilization against aggregation, selectivity against a desired target or for surfactant-mediated self-organization. INPs are necessary coated by an intended or accidental coating which contributes to the final reactivity. Thus, the same core material could exhibit different behavior depending on the nature of its surface coating and its aggregation state.

\subsection{Surface chemistry and phase transfer}

Although there have been many significant developments in the synthesis of INPs, maintaining their stability for long times avoiding its aggregation it is an important issue yet to be deeply explored. Pure metals, such as $\mathrm{Fe}, \mathrm{Co}, \mathrm{Ni}$ and their metal alloys as well as 
quantum dots (QDs) and Au NPs are usually synthesized in organic solvents and then stabilized using hydrophobic surfactants which provide steric stabilization of the particles (Peng et al., 2000; Puntes et al., 2001; Talapin et al., 2001). The general structure of the surfactant consists of a head group that "sticks" (adsorbed or chemically linked) to the INP's surface while the other end points towards the solution and provides colloidal stability. For biological applications, surface coating should be polar to provide high aqueous solubility and prevent INPs' aggregation and hence the hydrophobic surfactant has to be either replaced by others hydrophilic surfactant molecules in a ligand exchange reaction (Aldana et al., 2001; Gerion et al., 2001) or, alternatively, encapsulated within a polymeric sphere (Pöselt et al., 2009). In this way, by choosing the surfactant molecules, it is possible not only to adjust the surface properties of the particles but also tune its final reactivity. All of these surface modifications alter the chemical composition of INP's surface and therefore, their integration in different environments. An interesting example was the possibility to tune the toxicity of $\mathrm{C}_{60}$ by modifying the chemical nature of their surface (Sayes et al., 2004). $\mathrm{C}_{60}$ is an hydrophobic organic nanomaterial that forms aggregates when, pristine, gets in contact with water. These aggregates are cytotoxic at low concentration ( 20 parts per billion) causing cell death via disruption of cell membranes and oxidation of lipids. However, the increase of the solubility of fullerene derivatives decreases the toxic pronounced effects, obtaining a toxicity seven orders of magnitude lower in the case of $\mathrm{C}_{60}(\mathrm{OH})_{24}$. Other similar examples are the coating of carbon nanotubes (CNTs) with heparin (Murugesan et al., 2006) or poly(L-lactide) (Zhang et al., 2006) to yield biocompatible structures. Although this increase of solubility may lower the toxicity of nanomaterials, the biopersistence of these coatings is as essential as the knowledge about the bioavailability of the core material, which could exhibit intrinsic toxic properties.

\subsection{Surface chemistry and functionalization}

One of the most challenging ligand exchange reactions is the INPs functionalization for biomedical applications. In biomedicine, INPs have to be functionalized in order to selectively interact with biological targets. For this purpose, they are usually coated with biological molecules such as antibodies (Wang et al., 2002; El-Sayed et al., 2005), aptamers (Farokhzad et al., 2006), peptides (Kogan et al., 2006; Bastús et al., 2009), and oligonucleotides (Rosi et al., 2006). Some relevant examples are the functionalization of INPs with uptake ligands that specifically bind to receptors of the cell membrane (ex. transferrin (Wagner et al., 1994)), vector ligands that specifically interact with receptors which are overexpressed on the cell surface (Dixit et al., 2006) and peptides that facilitates crossing the cell membrane, either using cell penetrating peptides (Tkachenko et al., 2003; Pujals et al., 2009) or achieving the release of the INP to the cytosol with membrane-disruptive peptides (Han et al., 2006).

However, coatings used for INPs may not be persistent and could be metabolized exposing INP's core. Vector and targeting agents bind usually to INPs' surface by reactive (terminal) moieties. Thus, thiols, amines and carboxilic acids strongly bind to metal, semiconductor and magnetic cores with different and specific affinities. As a consequence of these different activities it is necessary to be aware of the surfactant exchange possibilities: If INP's media is rich in new species that bind stronger than those already present at the INP's surface, a ligand exchange process would take place. This is the case of Au NPs coated with amine or 
carboxilic groups and further exposed to thiol molecules (Woehrle et al., 2005). In fact, it has even been observed that Au NPs coated with thiol molecules may undergo a ligand exchange process if other thiols are present in solution at similar or higher concentrations. Additionally, this process could lead to a decrease of INP's solubility and a consequent nonreversible aggregation. In more sophisticated situations, as in the case of alloys presenting different types of surface atoms, they may spontaneously segregate forming a core-shell structure (atoms with lower surface tension migrates outwards at room temperature conditions (Margeat et al., 2007)), specially for smaller INPs. This phenomenon directly represents important modification of the INP's surface coating. Other studies have been shown that surface coating can be weathered either by its exposition to oxigen-rich environments or by ultraviolet (UV) irradiation (Rancan et al., 2002; Derfus et al., 2004).

\subsection{Surface chemistry and protein corona}

As previously mentioned, surface coating modifications are not always intended. They can eventually be accidental. One interesting case is the modification of INP's surface when exposed to biological fluids and their non-specific binding of media proteins (Bastús et al., 2009). This is the case of loosely coated INPs, such as citrate-stabilized Au NPs, where citrate molecules are immediately replaced by media proteins. This process, known as INP's protein corona (INP-PC), is one of the most significant alterations and may, in turn, strongly influence the biocompatibility and biodistribution of these INPs (Casals et al., 2010). INP-PC is a process governed by the competitive time-dependent adsorption of complex mixture of proteins (as serum) by a finite number of surface sites (Vroman, 1962). Thus, highest mobility proteins arrive first and are later (may take several hours) replaced by less motile proteins that have a higher affinity for the surface (Slack \& Horbett, 1995). Therefore, after exposition to cell culture media, INPs coating evolves in a time-dependent manner from a soft PC, a transient agglomeration of proteins onto INP's surface, to a hard PC, a dense albumin-rich proteic coating (Casals et al., 2010). This modifications of INP's coating alter INP's reactivity and strongly determine INP-biology interactions, since they are expected to happen at different time-scales. Whereas the removal of particles from the bloodstream takes place in a few minutes, interactions with cells of distant organs may be days after the exposure. Although this PC coating may increase the biocompatibility of the material, it may also alter their toxicity profile, something that has to be carefully considered before using INPs in biomedical applications. All in all, the increasing number of recently publications (Dobrovolskaia \& McNeil, 2007), which include the study of different materials such as $\mathrm{Au}$ (Casals et al., 2010), $\mathrm{Ag}, \mathrm{Fe}_{2} \mathrm{O}_{3}, \mathrm{CoO}, \mathrm{CeO}_{2}$ (Casals et al., 2011) FePt and CdSe/ZnS (Rocker et al., 2009) and the biological implications of the process, indicates the increasing importance of the topic.

\section{Reactivity between Inorganic nanoparticles in a colloidal solution}

INPs are in a constant Brownian movement which force their collisions towards an aggregated state. Although this reactivity is often undesirable (some physico-chemical properties of INPs are restricted to individual particles in non-physical contact) it can be used as driving force for the formation of more complex structures by an oriented attached mechanism. 


\subsection{Reactivity and agglomeration}

The revolutionary control of physico-chemical properties of nanostructured materials is restricted to individual particles in non-physical contact. Therefore, INP's surface needs to be stabilized in order to avoid irreversible agglomeration and, consequently, there is a significant effort to obtain isolated INPs during long periods of time, which is usually achieved by electrostatic, steric or electro-steric means (Roucoux et al., 2002). In fact, this may be one of the critical differences with the previously existing INPs, since natural and un-intentional occurring INPs tend to agglomerate readily. The degree of agglomeration has relevant consequences on the final behavior of the nanometric material. For instance, INPs used for sunscreens are usually composed of large agglomerates of nanometric domains (Bastús et al., 2008). Although these agglomerates are still efficient sun blockers, their optical properties are less intense than the individual INPs. Additionally, their large size avoids the penetration of such particles beneath the external skin.

INPs' aggregation can be exploited to be used as test to probe either the success of its functionalization or the presence of biological molecules (Figure 7). Metal particles
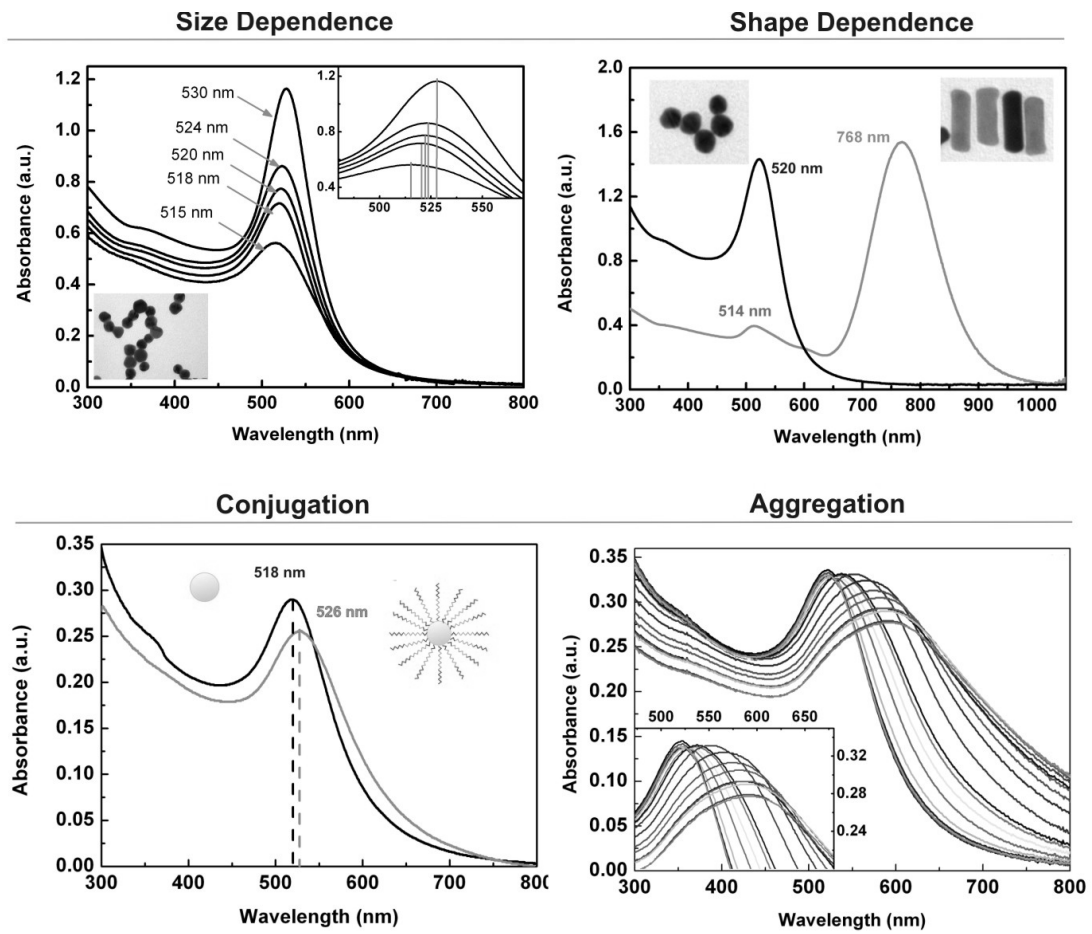

Fig. 7. Optical properties of gold nanoparticles. The position of the surface plasmon resonant band depends on the size (A) and shape (B) of Au NPs. This peak position depends on the chemical composition of particle surfactant shell (by changing the refractive index of the surrounding environment), being therefore sensible to functionalization processes $(C)$. The aggregation of Au NPs correlates with a red-shift of the SPR band position along with an increase in the absorbance from 600 to $800 \mathrm{~nm}(\mathrm{D})$. 
(especially $\mathrm{Au}$ and $\mathrm{Ag}$ ) interact resonantly with visible light absorbing a certain fraction of the visible wavelengths while another fraction is reflected. Small particles absorbs resonantly light in the blue region $(\sim 500 \mathrm{~nm})$ while as Au NP's size increases, surface plasmon band (SPR) shifts to longer wavelengths, yielding Au NPs a pale-blue colour. SPR band is not only influenced by INP's size, it depends as well on its shape, the chemical composition of the INP's surfactant shell and its agglomeration state (due to dipole coupling between the plasmons of neighbouring particles). This property allows the use of Au NPs as sensors. Thus, when particles aggregate absorption wavelengths red-shifts and the colloidal solution changes its color from red to purple. One of the most typical examples that takes advantage of SPR changes is the colorimetric test to detect single-stranded oligonucleotide targets by using DNA-modified Au NP probes. Thus, two species are present in solution such that each is functionalized with a DNA-oligonucleotide complementary to one half of a given target oligonucleotide. Mixing the two probes with the target results in the formation of a polymeric network of DNA-Au-NPs with a concomitant red-to-purple colour change (Mirkin et al., 1996). Similarly, INP's aggregation can be use as a test to evaluate the INP's stabilization mechanism which allow, under certain conditions, determine the success of INP's functionalization process. Thus, electrostatically-stabilized citrate-coated Au NPs easily aggregate when changing the ionic strength and/or the $\mathrm{pH}$ of the medium in which they are solved, while peptidic conjugates with significant steric repulsion (stabilized by the interactions of molecules side chains or domains) withstand much higher changes without compromising stability.

\subsection{Reactivity and shape control}

The reactivity of colloidal INPs against other INPs is the driving force for the formation of complex structures by an oriented attachment mechanism. Thus, nearly isotropic NCs previously formed in solution coalesce and fuse along some preferential crystallographic directions leading to wires (Tang et al., 2002), rings (Cho et al., 2005) or even sheets (Schliehe et al., 2010). Although this mechanism is not completely understood, one possible explanation is the NC's coalescence along certain directions, which might reduce the overall surface energy by eliminating some high energy facets. Additionally, this process may be facilitated when the organic shell is partially removed from the surface of the initial seed particle or when weakly coordinating molecules are used as stabilizers, so that dipole-dipole inter-particle interactions are enhanced and one-directional NC attachment is spontaneously promoted (Cozzoli et al., 2006).

\section{Conclusion}

This chapter overviews the particular physical-chemical properties of INPs in order to understand what factors determine its chemical reactivity and thus its applicability in nanobiomedicine and catalysis among others. According to this, the critical factors that determine the interactions of INPs with surrounding environment are: i) Effects of inorganic core's size and shape, ii) the particular reactivity of the coating molecule, iii) the surface molecule substitution and ligand exchange, iv) the interactions with ions present in the colloidal solution and v) the cooperative effects with other NPs present in solution. Along with this study, toxicological aspects associated to the reactivity of INPs (size, shape, chemical composition and structure) have been widely discussed. 


\section{Acknowledgment}

The authors acknowledge financial support from the grants "Plan Nacional" from the Spanish Ministry of Science and Innovation (MAT2009-14734-C02-01) and "Nanotecnologías en biomedicina (NANOBIOMED)" from the Consolider-Ingenio 2010 Program (CSD200600012).

\section{References}

Ahrenkiel, S. P., Micic, O. I., Miedaner, A., Curtis, C. J., Nedeljkovic, J. M. \& Nozik, A. J. (2003). Synthesis and Characterization of Colloidal InP Quantum Rods. Nano Letters, Vol.3, No. 6, pp. 833-837, ISNN 1530-6984

Aldana, J., Wang, Y. A. \& Peng, X. G. (2001). Photochemical instability of CdSe nanocrystals coated by hydrophilic thiols. Journal of the American Chemical Society, Vol.123, No. 36, pp. 8844-8850, ISNN 0002-7863

Alivisatos, P. (2001). Less is more in medicine. Scientific American, Vol.285, No. 3, pp. 66-73, ISNN 0036-8733

Auffan, M., Rose, J., Bottero, J.-Y., Lowry, G. V., Jolivet, J.-P. \& Wiesner, M. R. (2009). Towards a definition of inorganic nanoparticles from an environmental, health and safety perspective. Nat Nano, Vol.4, No. 10, pp. 634-641, ISNN 1748-3387

Barghorn, S., Nimmrich, V., Striebinger, A., Krantz, C., Keller, P., Janson, B., Bahr, M., Schmidt, M., Bitner, R. S., Harlan, J., Barlow, E., Ebert, U. \& Hillen, H. (2005). Globular amyloid-peptide 1-42 oligome ;a homogenous and stable neuropathological protein in Alzheimer's disease. Journal of Neurochemistry, Vol.95, No. 3, pp. 834-847, ISNN

Bastús, N. G., Casals, E., Vázquez-Campos, S. \& Puntes, V. (2008). Reactivity of engineered inorganic nanoparticles and carbon nanostructures in biological media. Nanotoxicology, Vol.2, No. 3, pp. 99 - 112, ISNN 1743-5390

Bastús, N. G., Comenge, J. \& Puntes, V. Kinetically Controlled Seeded Growth Synthesis of Citrate-Stabilized Gold Nanoparticles of up to $200 \mathrm{~nm}$ : Size Focusing versus Ostwald Ripening. Langmuir, Vol.27, No. 17, pp. 11098-11105, ISNN 0743-7463

Bastús, N. G., Sanchez-Tillo, E., Pujals, S., Farrera, C., Lopez, C., Giralt, E., Celada, A., Lloberas, J. \& Puntes, V. (2009). Homogeneous Conjugation of Peptides onto Gold Nanoparticles Enhances Macrophage Response. ACS Nano, Vol.3, No. 6, pp. 13351344, ISNN 1936-0851

Bratlie, K. M., Lee, H., Komvopoulos, K., Yang, P. \& Somorjai, G. A. (2007). Platinum Nanoparticle Shape Effects on Benzene Hydrogenation Selectivity. Nano Letters, Vol.7, No. 10, pp. 3097-3101, ISNN 1530-6984

Burda, C., Chen, X., Narayanan, R. \& El-Sayed, M. A. (2005). Chemistry and Properties of Nanocrystals of Different Shapes. Chemical Reviews, Vol.105, No. 4, pp. 1025-1102, ISNN 0009-2665

Cabot, A., Alivisatos, A. P., Puntes, V. F., Balcells, L., Iglesias, O. \& Labarta, A. (2009). Magnetic domains and surface effects in hollow maghemite nanoparticles. Physical Review B, Vol.79, No. 9, pp. 094419

Cabot, A., Puntes, V. F., Shevchenko, E., Yin, Y., Balcells, L. s., Marcus, M. A., Hughes, S. M. \& Alivisatos, A. P. (2007). Vacancy Coalescence during Oxidation of Iron 
Nanoparticles. Journal of the American Chemical Society, Vol.129, No. 34, pp. 1035810360, ISNN 0002-7863

Casals, E., Pfaller, T., Duschl, A., Oostingh, G. J. \& Puntes, V. (2010). Time Evolution of the Nanoparticle Protein Corona. ACS Nano, Vol.4, No. 7, pp. 3623-3632, ISNN 19360851

Casals, E., Pfaller, T., Duschl, A., Oostingh, G. J. \& Puntes, V. (2011). Hardening of the Nanoparticle Protein Corona in Metal $(\mathrm{Au}, \mathrm{Ag})$ and Oxide $\left(\mathrm{Fe}_{3} \mathrm{O}_{4}, \mathrm{CoO}\right.$ and $\left.\mathrm{CeO}_{2}\right)$ Nanoparticles. Small, Vol.7, No. 24, pp. 3479-3486

Casals, E., Vázquez-Campos, S., Bastús, N. G. \& Puntes, V. (2008). Distribution and potential toxicity of engineered inorganic nanoparticles and carbon nanostructures in biological systems. TrAC Trends in Analytical Chemistry, Vol.27, No. 8, pp. 672-683, ISNN 0165-9936

Cho, K.-S., Talapin, D. V., Gaschler, W. \& Murray, C. B. (2005). Designing PbSe Nanowires and Nanorings through Oriented Attachment of Nanoparticles. Journal of the American Chemical Society, Vol.127, No. 19, pp. 7140-7147, ISNN 0002-7863

Connor, E. E., Mwamuka, J., Gole, A., Murphy, C. J. \& Wyatt, M. D. (2005). Gold nanoparticles are taken up by human cells but do not cause acute cytotoxicity. Small, Vol.1, No. 3, pp. 325-327, ISNN 1613-6810

Cozzoli, P. D., Pellegrino, T. \& Manna, L. (2006). Synthesis, properties and perspectives of hybrid nanocrystal structures. Chemical Society Reviews, Vol.35, No. 11, pp. 11951208, ISNN 0306-0012

Derfus, A. M., Chan, W. C. W. \& Bhatia, S. N. (2004). Probing the cytotoxicity of semiconductor quantum dots. Nano Letters, Vol.4, No. 1, pp. 11-18, ISNN 1530-6984

Diallo, M. S. \& Savage, N. (2005). Nanoparticles and Water Quality. Journal of Nanoparticle Research, Vol.7, No. 4, pp. 325-330, ISNN 1388-0764

Dixit, V., VandenBossche, J., Sherman, D. M., Thompson, D. H. \& Andres, R. P. (2006). Synthesis and Grafting of Thioctic Acid-PEG-Folate Conjugates onto $\mathrm{Au}$ Nanoparticles for Selective Targeting of Folate Receptor-Positive Tumor Cells. Bioconjugate Chem., Vol.17, No. 3, pp. 603-609, ISNN 1043-1802

Dobrovolskaia, M. A. \& McNeil, S. E. (2007). Immunological properties of engineered nanomaterials. Nat Nano, Vol.2, No. 8, pp. 469-478, ISNN 1748-3387

El-Sayed, I. H., Huang, X. \& El-Sayed, M. A. (2005). Surface Plasmon Resonance Scattering and Absorption of anti-EGFR Antibody Conjugated Gold Nanoparticles in Cancer Diagnostics: Applications in Oral Cancer. Nano Lett., Vol.5, No. 5, pp. 829-834, ISNN 1530-6984

Farokhzad, O. C., Cheng, J. J., Teply, B. A., Sherifi, I., Jon, S., Kantoff, P. W., Richie, J. P. \& Langer, R. (2006). Targeted nanoparticle-aptamer bioconjugates for cancer chemotherapy in vivo. Proceedings of the National Academy of Sciences of the United States of America, Vol.103, No. 16, pp. 6315-6320, ISNN 0027-8424

Franklin, N. M., Rogers, N. J., Apte, S. C., Batley, G. E., Gadd, G. E. \& Casey, P. S. (2007). Comparative Toxicity of Nanoparticulate $\mathrm{ZnO}$, Bulk $\mathrm{ZnO}$, and $\mathrm{ZnCl} 2$ to a Freshwater Microalga (Pseudokirchneriella subcapitata): The Importance of Particle Solubility. Environmental Science \& Technology, Vol.41, No. 24, pp. 8484-8490, ISNN 0013-936X

Freitas, R. A. J. (1999). Nanomedicine, Volume I: Basic Capabilities. Georgetown, Landes Bioscience., ISNN 978-1-57059-680-3 
Garcia, A., Espinosa, R., Delgado, L., Casals, E., Gonzalez, E., Puntes, V., Barata, C., Font, X. \& Sanchez, A. (2010). Acute toxicity of cerium oxide, titanium oxide and iron oxide nanoparticles using standardized tests. Desalination, Vol.269, No. 1-3, pp. 136-141, ISNN 0011-9164

Gerion, D., Pinaud, F., Williams, S. C., Parak, W. J., Zanchet, D., Weiss, S. \& Alivisatos, A. P. (2001). Synthesis and Properties of Biocompatible Water-Soluble Silica-Coated CdSe/ZnS Semiconductor Quantum Dots. J. Phys. Chem. B, Vol.105, No. 37, pp. 8861-8871, ISNN 1520-6106

Gojova, A., Guo, B., Kota, R. S., Rutledge, J. C., Kennedy, I. M. \& Barakat, A. I. (2007). Induction of inflammation in vascular endothelial cells by metal oxide nanoparticles: Effect of particle composition. Environmental Health Perspectives, Vol.115, No. 3, pp. 403-409, ISNN 0091-6765

Goldstein, A. N., Echer, C. M. \& Alivisatos, A. P. (1992). Melting in Semiconductor Nanocrystals. Science, Vol.256, No. 5062, pp. 1425-1427,

Grebinski, J. W., Hull, K. L., Zhang, J., Kosel, T. H. \& Kuno, M. (2004). Solution-Based Straight and Branched CdSe Nanowires. Chemistry of Materials, Vol.16, No. 25, pp. 5260-5272, ISNN 0897-4756

Gupta, A. K. \& Gupta, M. (2005). Cytotoxicity suppression and cellular uptake enhancement of surface modified magnetic nanoparticles. Biomaterials, Vol.26, No. 13, pp. 15651573, ISNN 0142-9612

Gupta, K. \& Ghosh, U. C. (2009). Arsenic removal using hydrous nanostructure iron(III)titanium(IV) binary mixed oxide from aqueous solution. Journal of Hazardous Materials, Vol.161, No. 2-3, pp. 884-892, ISNN 0304-3894

Han, G., You, C.-C., Kim, B.-j., Turingan, R. S., Forbes, N. S., Martin, C. T. \& Rotello, V. M. (2006). Light-Regulated Release of DNA and Its Delivery to Nuclei by Means of Photolabile Gold Nanoparticles. Angewandte Chemie International Edition, Vol.45, No. 19 , pp. 3165-3169, ISNN 1521-3773

Henglein, A. \& Giersig, M. (2000). Optical and Chemical Observations on Gold-Mercury Nanoparticles in Aqueous Solution. The Journal of Physical Chemistry B, Vol.104, No. 21, pp. 5056-5060, ISNN 1520-6106

$\mathrm{Hu}$, J., Chen, G. \& Lo, I. M. C. (2005). Removal and recovery of $\mathrm{Cr}(\mathrm{VI})$ from waste water by maghemite nanoparticles. Water Research, Vol.39, No. 18, pp. 4528-4536, ISNN 00431354

Hu, J., Li, L.-s., Yang, W., Manna, L., Wang, L.-w. \& Alivisatos, A. P. (2001). Linearly Polarized Emission from Colloidal Semiconductor Quantum Rods. Science, Vol.292, No. 5524, pp. 2060-2063

Hvolbaek, B., Janssens, T. V. W., Clausen, B. S., Falsig, H., Christensen, C. H. \& Norskov, J. K. (2007). Catalytic activity of Au nanoparticles. Nano Today, Vol.2, No. 4, pp. 14-18, ISNN 1748-0132

Ito, A., Sun, X. \& Tateishi, T. (2001). In-vitro analysis of metallic particles, colloidal nanoparticles and ions in wear-corrosion products of SUS317L stainless steel. Materials Science and Engineering: C, Vol.17, No. 1-2, pp. 161-166, ISNN 0928-4931

Kamat, P. V. (2007). Meeting the Clean Energy Demand: A Nanostructure Architectures for Solar Energy Conversion. The Journal of Physical Chemistry C, Vol.111, No. 7, pp. 2834-2860, ISNN 1932-7447 
Karakoti, A., Monteiro-Riviere, N., Aggarwal, R., Davis, J., Narayan, R., Self, W., McGinnis, J. \& Seal, S. (2008). Nanoceria as antioxidant: Synthesis and biomedical applications. JOM Journal of the Minerals, Metals and Materials Society, Vol.60, No. 3, pp. 33-37, ISNN 1047-4838

Karn, B., Kuiken, T. \& Otto, M. (2009). Nanotechnology and in Situ Remediation: A Review of the Benefits and Potential Risks. Environ Health Perspect, Vol.117, No. 12, pp. 1813-1831

Katsikas, L., Gutierrez, M. \& Henglein, A. (1996). Bimetallic Colloids: Silver and Mercury. The Journal of Physical Chemistry, Vol.100, No. 27, pp. 11203-11206, ISNN 0022-3654

Kogan, M. J., Bastus, N. G., Amigo, R., Grillo-Bosch, D., Araya, E., Turiel, A., Labarta, A., Giralt, E. \& Puntes, V. F. (2006). Nanoparticle-mediated local and remote manipulation of protein aggregation. Nano Letters, Vol.6, No. 1, pp. 110-115, ISNN 1530-6984

Kumar, S. \& Nann, T. (2006). Shape Control of II-VI Semiconductor Nanomaterials. Small, Vol.2, No. 3, pp. 316-329, ISNN 1613-6829

Lazaro, F. J., Abadia, A. R., Romero, M. S., Gutierrez, L., Lazaro, J. \& Morales, M. P. (2005). Magnetic characterisation of rat muscle tissues after subcutaneous iron dextran injection. Biochimica Et Biophysica Acta-Molecular Basis of Disease, Vol.1740, No. 3, pp. 434-445, ISNN 0925-4439

Li, Y. \& Somorjai, G. A. (2010). Nanoscale Advances in Catalysis and Energy Applications. Nano Letters, Vol.10, No. 7, pp. 2289-2295, ISNN 1530-6984

Lisha, K., Anshup, A. \& Pradeep, T. (2009). Towards a practical solution for removing inorganic mercury from drinking water using gold nanoparticles. Gold Bulletin, Vol.42, No. 2, pp. 144-152, ISNN 0017-1557

López, X. \& Castaño, V. M. (2008). Chromium Removal from Industrial Water Through Functionallized Nanoparticles J. Nanosci. Nanotechnol, Vol.8, No., pp. 5733-5738 ISNN

Manna, L., Scher, E. C. \& Alivisatos, A. P. (2000). Synthesis of Soluble and Processable Rod-, Arrow-, Teardrop-, and Tetrapod-Shaped CdSe Nanocrystals. Journal of the American Chemical Society, Vol.122, No. 51, pp. 12700-12706, ISNN 0002-7863

Margeat, O., Ciuculescu, D., Lecante, P., Respaud, M., Amiens, C. \& Chaudret, B. (2007). NiFe nanoparticles: A soft magnetic material? Small, Vol.3, No. 3, pp. 451-458, ISNN 1613-6810

Meyns, M., Bastus, N. G., Cai, Y., Kornowski, A., Juarez, B. H., Weller, H. \& Klinke, C. (2010). Growth and reductive transformation of a gold shell around pyramidal cadmium selenide nanocrystals. Journal of Materials Chemistry, Vol. 20, pp. 1060210605, ISNN 0959-9428

Mirkin, C. A., Letsinger, R. L., Mucic, R. C. \& Storhoff, J. J. (1996). A DNA-based method for rationally assembling nanoparticles into macroscopic materials. Nature, Vol.382, No. 6592, pp. 607-609, ISNN 0028-0836

Mokari, T., Rothenberg, E., Popov, I., Costi, R. \& Banin, U. (2004). Selective growth of metal tips onto semiconductor quantum rods and tetrapods. Science, Vol.304, No. 5678, pp. 1787-1790, ISNN 0036-8075

Murugesan, S., Park, T. J., Yang, H. C., Mousa, S. \& Linhardt, R. J. (2006). Blood compatible carbon nanotubes - Nano-based neoproteoglycans. Langmuir, Vol.22, No. 8, pp. 3461-3463, ISNN 0743-7463 
Nikoobakht, B. \& El-Sayed, M. A. (2003). Preparation and growth mechanism of gold nanorods using seed-mediated growth method. Chemistry of Materials, Vol.15, No. 10, pp. 1957-1962, ISNN 0897-4756

Oberdörster, G. (2000). Toxicology of ultrafine particles: in vivo studies. Philosophical Transactions of the Royal Society of London Series a-Mathematical Physical and Engineering Sciences, Vol.358, No. 1775, pp. 2719-2739, ISNN 1364-503X

Oberdörster, G., Finkelstein, J., Johnston, C., Gelein, R., Cox, C., Baggs, R. \& Elder, A. (2000). Acute Pulmonary Effects of Ultrafine Particles in Rats and Mice. Res Rep Health Eff Inst, Vol.96, No., pp. 5-74

Oberdorster, G., Oberdorster, E. \& Oberdorster, J. (2005). Nanotoxicology: an emerging discipline evolving from studies of ultrafine particles. Environ Health Perspect, Vol.113, No. 7, pp. 823-39, ISNN 0091-6765 (Print)

Overbury, S. H., Schwartz, V., Mullins, D. R., Yan, W. \& Dai, S. (2006). Evaluation of the Au size effect: $\mathrm{CO}$ oxidation catalyzed by $\mathrm{Au} / \mathrm{TiO}_{2}$. Journal of Catalysis, Vol.241, No. 1, pp. 56-65, ISNN 0021-9517

Pacheco, S., Medina, M., Valencia, F. \& Tapia, J. (2006). Removal of Inorganic Mercury from Polluted Water Using Structured Nanoparticles, ASCE.

Peng, X., Manna, L., Yang, W., Wickham, J., Scher, E., Kadavanich, A. \& Alivisatos, A. P. (2000). Shape control of CdSe nanocrystals. Nature, Vol.404, No. 6773, pp. 59-61, ISNN 0028-0836

Peng, X. G., Manna, L., Yang, W. D., Wickham, J., Scher, E., Kadavanich, A. \& Alivisatos, A. P. (2000). Shape control of CdSe nanocrystals. Nature, Vol.404, No. 6773, pp. 59-61, ISNN 0028-0836

Pérez-Juste, J., Pastoriza-Santos, I., Liz-Marzán, L. M. \& Mulvaney, P. (2005). Gold nanorods: Synthesis, characterization and applications. Coordination Chemistry Reviews, Vol.249, No. 17-18, pp. 1870-1901, ISNN 0010-8545

Pöselt, E., Fischer, S., Foerster, S. \& Weller, H. (2009). Highly Stable Biocompatible Inorganic Nanoparticles by Self-Assembly of Triblock-Copolymer Ligands Langmuir, Vol.25, No. 24, pp. 13906-13913, ISNN 0743-7463

Pujals, S., Bastus, N. G., Pereiro, E., Lopez-Iglesias, C., Punte, V. F., Kogan, M. J. \& Giralt, E. (2009). Shuttling Gold Nanoparticles into Tumoral Cells with an Amphipathic Proline-Rich Peptide. Chembiochem, Vol.10, No. 6, pp. 1025-1031, ISNN 1439-4227

Puntes, V. F., Krishnan, K. M. \& Alivisatos, A. P. (2001). Colloidal nanocrystal shape and size control: The case of cobalt. Science, Vol.291, No. 5511, pp. 2115-2117, ISNN 0036-8075

Rancan, F., Rosan, S., Boehm, F., Cantrell, A., Brellreich, M., Schoenberger, H., Hirsch, A. \& Moussa, F. (2002). Cytotoxicity and photocytotoxicity of a dendritic C-60 monoadduct and a malonic acid C-60 tris-adduct on Jurkat cells. Journal of Photochemistry and Photobiology B-Biology, Vol.67, No. 3, pp. 157-162, ISNN 1011-1344

Rocker, C., Potzl, M., Zhang, F., Parak, W. J. \& Nienhaus, G. U. (2009). A quantitative fluorescence study of protein monolayer formation on colloidal nanoparticles. Nat Nano, Vol.4, No. 9, pp. 577-580, ISNN 1748-3387

Rosi, N. L., Giljohann, D. A., Thaxton, C. S., Lytton-Jean, A. K. R., Han, M. S. \& Mirkin, C. A. (2006). Oligonucleotide-modified gold nanoparticles for intracellular gene regulation. Science, Vol.312, No. 5776, pp. 1027-1030, ISNN 0036-8075 
Roucoux, A., Schulz, J. r. \& Patin, H. (2002). Reduced Transition Metal Colloids: Novel Family of Reusable Catalysts? Chemical Reviews, Vol.102, No. 10, pp. 3757-3778, ISNN 0009-2665

Savage, N. \& Diallo, M. S. (2005). Nanomaterials and Water Purification: Opportunities and Challenges. Journal of Nanoparticle Research, Vol.7, No. 4, pp. 331-342, ISNN 13880764

Sayes, C. M., Fortner, J. D., Guo, W., Lyon, D., Boyd, A. M., Ausman, K. D., Tao, Y. J., Sitharaman, B., Wilson, L. J., Hughes, J. B., West, J. L. \& Colvin, V. L. (2004). The differential cytotoxicity of water-soluble fullerenes. Nano Letters, Vol.4, No. 10, pp. 1881-1887, ISNN 1530-6984

Schliehe, C., Juarez, B. H., Pelletier, M., Jander, S., Greshnykh, D., Nagel, M., Meyer, A., Foerster, S., Kornowski, A., Klinke, C. \& Weller, H. (2010). Ultrathin PbS Sheets by Two-Dimensional Oriented Attachment. Science, Vol.329, No. 5991, pp. 550-553

Slack, S. M. \& Horbett, T. A. (1995). The Vroman Effect. Proteins at Interfaces II, American Chemical Society. 602: 112-128.

Smigelskas, A. D. \& Kirkendall, E. O. (1947). Zinc Diffusion in Alpha Brass. Transactions of the American Institute of Mining and Metallurgical Engineers, Vol.171, No. 130-142

Son, D. H., Hughes, S. M., Yin, Y. \& Paul Alivisatos, A. (2004). Cation Exchange Reactions in Ionic Nanocrystals. Science, Vol.306, No. 5698, pp. 1009-1012

Sun, Y., Mayers, B. T. \& Xia, Y. (2002). Template-Engaged Replacement Reaction: A OneStep Approach to the Large-Scale Synthesis of Metal Nanostructures with Hollow Interiors. Nano Letters, Vol.2, No. 5, pp. 481-485, ISNN 1530-6984

Talapin, D. V., Rogach, A. L., Kornowski, A., Haase, M. \& Weller, H. (2001). Highly luminescent monodisperse CdSe and CdSe/ZnS nanocrystals synthesized in a hexadecylamine-trioctylphosphine oxide-trioctylphospine mixture. Nano Letters, Vol.1, No. 4, pp. 207-211, ISNN 1530-6984

Tang, Z., Kotov, N. A. \& Giersig, M. (2002). Spontaneous Organization of Single CdTe Nanoparticles into Luminescent Nanowires. Science, Vol.297, No. 5579, pp. 237-240

Taniguchi, S., Green, M. \& Lim, T. (2011). The Room-Temperature Synthesis of Anisotropic CdHgTe Quantum Dot Alloys: A Molecular Welding Effect. Journal of the American Chemical Society, Vol.133, No. 10, pp. 3328-3331, ISNN 0002-7863

Tao, A. R., Habas, S. \& Yang, P. (2008). Shape Control of Colloidal Metal Nanocrystals. Small, Vol.4, No. 3, pp. 310-325, ISNN 1613-6829

Tkachenko, A. G., Xie, H., Coleman, D., Glomm, W., Ryan, J., Anderson, M. F., Franzen, S. \& Feldheim, D. L. (2003). Multifunctional Gold Nanoparticle-Peptide Complexes for Nuclear Targeting. J. Am. Chem. Soc., Vol.125, No. 16, pp. 4700-4701, ISNN 00027863

Trentler, T. J., Hickman, K. M., Goel, S. C., Viano, A. M., Gibbons, P. C. \& Buhro, W. E. (1995). Solution-Liquid-Solid Growth of Crystalline III-V Semiconductors: An Analogy to Vapor-Liquid-Solid Growth. Science, Vol.270, No. 5243, pp. 1791-1794

Vroman, L. (1962). Effect of Adsorbed Proteins on the Wettability of Hydrophilic and Hydrophobic Solids. Nature, Vol.196, No. 4853, pp. 476-477

Wagner, E., Curiel, D. \& Cotten, M. (1994). Delivery of drugs, proteins and genes into cells using transferrin as a ligand for receptor-mediated endocytosis. Advanced Drug Delivery Reviews, Vol.14, No. 1, pp. 113-135 
Wang, S., Mamedova, N., Kotov, N. A., Chen, W. \& Studer, J. (2002). Antigen/ Antibody Immunocomplex from CdTe Nanoparticle Bioconjugates. Nano Lett., Vol.2, No. 8, pp. 817-822, ISNN 1530-6984

Weissleder, R., Stark, D. D., Engelstad, B. L., Bacon, B. R., Compton, C. C., White, D. L., Jacobs, P. \& Lewis, J. (1989). Superparamagnetic Iron-Oxide - Pharmacokinetics and Toxicity. American Journal of Roentgenology, Vol.152, No. 1, pp. 167-173, ISNN 0361$803 \mathrm{X}$

Woehrle, G. H., Brown, L. O. \& Hutchison, J. E. (2005). Thiol-functionalized, 1.5-nm gold nanoparticles through ligand exchange reactions: Scope and mechanism of ligand exchange. Journal of the American Chemical Society, Vol.127, No. 7, pp. 2172-2183, ISNN 0002-7863

Xu, C., Su, J., Xu, X., Liu, P., Zhao, H., Tian, F. \& Ding, Y. (2006). Low Temperature CO Oxidation over Unsupported Nanoporous Gold. Journal of the American Chemical Society, Vol.129, No. 1, pp. 42-43, ISNN 0002-7863

Yavuz, C. T., Mayo, J. T., Yu, W. W., Prakash, A., Falkner, J. C., Yean, S., Cong, L., Shipley, H. J., Kan, A., Tomson, M., Natelson, D. \& Colvin, V. L. (2006). Low-Field Magnetic Separation of Monodisperse $\mathrm{Fe}_{3} \mathrm{O}_{4}$ Nanocrystals. Science, Vol.314, No. 5801, pp. $964-$ 967

Yin, Y., Rioux, R. M., Erdonmez, C. K., Hughes, S., Somorjai, G. A. \& Alivisatos, A. P. (2004). Formation of Hollow Nanocrystals Through the Nanoscale Kirkendall Effect. Science, Vol.304, No. 5671, pp. 711-714

Zhang, D. H., Kandadai, M. A., Cech, J., Roth, S. \& Curran, S. A. (2006). Poly(L-lactide) (PLLA)/multiwalled carbon nanotube (MWCNT) composite: Characterization and biocompatibility evaluation. Journal of Physical Chemistry B, Vol.110, No. 26, pp. 12910-12915, ISNN 1520-6106

Zhang, J., Tang, Y., Lee, K. \& Ouyang, M. (2010). Nonepitaxial Growth of Hybrid Core-Shell Nanostructures with Large Lattice Mismatches. Science, Vol.327, No. 5973, pp. 16341638

Zhang, W. X. (2003). Nanoscale Iron Particles for Environmental Remediation: An Overview. Journal of Nanoparticle Research, Vol.5, No. 3, pp. 323-332, ISNN 1388-0764 


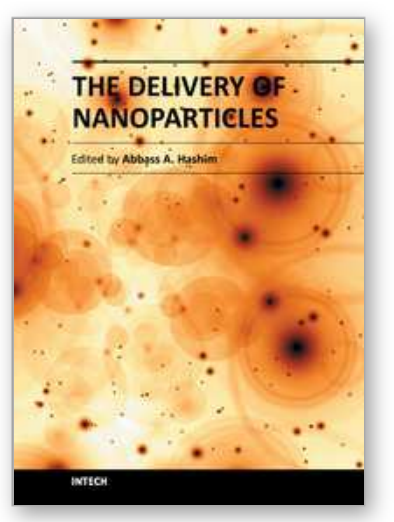

\author{
The Delivery of Nanoparticles \\ Edited by Dr. Abbass A. Hashim
}

ISBN 978-953-51-0615-9

Hard cover, 540 pages

Publisher InTech

Published online 16, May, 2012

Published in print edition May, 2012

Nanoparticle is a general challenge for today's technology and the near future observations of science. Nanoparticles cover mostly all types of sciences and manufacturing technologies. The properties of this particle are flying over today scientific barriers and have passed the limitations of conventional sciences. This is the reason why nanoparticles have been evaluated for the use in many fields. InTech publisher and the contributing authors of this book in nanoparticles are all overconfident to invite all scientists to read this new book. The book's potential was held until it was approached by the art of exploring the most advanced research in the field of nano-scale particles, preparation techniques and the way of reaching their destination. 25 reputable chapters were framed in this book and there were alienated into four altered sections; Toxic Nanoparticles, Drug Nanoparticles, Biological Activities and Nano-Technology.

\title{
How to reference
}

In order to correctly reference this scholarly work, feel free to copy and paste the following:

Neus G. Bastus, Eudald Casals, Isaac Ojea, Miriam Varon and Victor Puntes (2012). The Reactivity of Colloidal Inorganic Nanoparticles, The Delivery of Nanoparticles, Dr. Abbass A. Hashim (Ed.), ISBN: 978-95351-0615-9, InTech, Available from: http://www.intechopen.com/books/the-delivery-of-nanoparticles/thereactivity-of-colloidal-inorganic-nanoparticles

\section{INTECH}

open science | open minds

\author{
InTech Europe \\ University Campus STeP Ri \\ Slavka Krautzeka 83/A \\ 51000 Rijeka, Croatia \\ Phone: +385 (51) 770447 \\ Fax: +385 (51) 686166 \\ www.intechopen.com
}

\author{
InTech China \\ Unit 405, Office Block, Hotel Equatorial Shanghai \\ No.65, Yan An Road (West), Shanghai, 200040, China \\ 中国上海市延安西路65号上海国际贵都大饭店办公楼 405 单元 \\ Phone: +86-21-62489820 \\ Fax: +86-21-62489821
}


(C) 2012 The Author(s). Licensee IntechOpen. This is an open access article distributed under the terms of the Creative Commons Attribution 3.0 License, which permits unrestricted use, distribution, and reproduction in any medium, provided the original work is properly cited. 